Produto \& Produção, vol. 12, n. 1, p. 01 - 19, fev. 2011

\title{
Análise dos métodos de avaliação de investimentos e opções de controle de Risco para projetos internos de Tl em empresas de Tecnologia
}

\section{Rogério Feroldi Miorando}

Programa de Pós-Graduação em Engenharia de Produção - PPGEP/UFRGS

\author{
Alessandra Carla Ceolin \\ Programa de Pós-Graduação em Agronegócios - UFRGS
}

O ambiente competitivo em que as empresas de tecnologia estão inseridas exige que estas se adaptem de forma rápida às mudanças, buscando opções que tragam flexibilidade para seus investimentos. Muitos modelos de avaliação de investimentos têm falhado em capturar o valor desta flexibilidade. Este trabalho apresenta uma análise dos modelos de avaliação de investimentos utilizados por empresas de tecnologia em seus projetos de TI. Para isto, realizou-se uma pesquisa Survey com 34 empresas situadas no estado do Rio Grande do Sul. Os principais resultados mostram que (i) existe uma crescente exigência pela realização de análises de investimentos sempre que um investimento em TI é necessário; (ii) grande parte das empresas não realizam análises quantitativas de seus projetos; e (iii) as ações de contingência para os riscos estão desalinhadas ou subutilizadas se comparadas às alternativas propostas pela literatura. Isso oferece espaço para ganhos com métodos quantitativos que ofereçam maior flexibilidade, como é o caso de Opções Reais.

Palavras-chave: Análise de Investimentos, Tecnologia da Informação, Opções Reais.

The competitive environment where technology companies are inserted requires them to adapt quickly to changes, seeking options that bring flexibility for their investments. However, traditional methods of investment evaluation have failed to capture the value of this flexibility. This paper presents an analysis of investment evaluation models used by technology companies in their internal IT projects. For this, a survey was conducted with 34 companies located in the Rio Grande do Sul state. The main results show that: $(i)$ there is a growing demand for carrying out investment analysis when an investment in IT is necessary; (ii) most companies do not perform quantitative analysis of their projects; and (iii) the contingency actions to mitigate risks are misaligned or underused when compared to alternatives proposed by literature. This provides scope for gains in quantitative methods that offer greater flexibility, such as Real Options.

Keywords: Investment Analysis, Information Technology, Real Options. 


\section{INTRODUÇÃO}

O ambiente econômico no qual as empresas estão operando atualmente, marcado pela pressão crescente da globalização, faz do investimento um dos fatores mais importantes da vantagem competitiva. É importante que as empresas invistam em ativos intangíveis e em capacidades requeridas para a sua competitividade, tais como em pesquisa e desenvolvimento (P\&D), treinamento e tecnologias de informação (PORTER, 1992).

As empresas de tecnologia estão inseridas no centro deste cenário competitivo, o que tem exigido das mesmas uma rápida adaptação às mudanças, fazendo com que invistam em projetos que criem opções para seus investimentos, tornando-as mais flexíveis. No entanto, o uso estático dos métodos tradicionais de avaliação de investimentos tem se mostrado ineficiente para captar o valor desta flexibilidade.

A avaliação de investimentos em Tecnologia da Informação (TI) é considerada uma estrutura complexa. Em geral, este tipo de investimento é repleto de incertezas e muitas vezes os resultados obtidos são intangíveis, o que dificulta a quantificação de benefícios e custos. Devido a estas características dinâmicas dos projetos de $\mathrm{Tl}$, as ferramentas tradicionais de orçamentação de capital não são as mais adequadas para avaliar este tipo de investimento. A crítica está no fato de que estes métodos são baseados somente no retorno financeiro, não levando em consideração os fatores intangíveis como futura vantagem competitiva, futuras oportunidades e flexibilidade gerencial (SANTOS; PAMPLONA, 2005).

Este fato tem levado à busca de métodos mais sofisticados de avaliação de investimentos, capazes de trabalhar com a incerteza e proporcionar uma maior flexibilidade aos investimentos. A adoção da Teoria de Opções Reais apresenta-se como um método mais robusto para a análise econômica de risco e flexibilidade nos investimentos. O conceito básico das Opções Reais, de pensar os investimentos como opções, tem oferecido um novo nível ao processo de tomada de decisão em investimento de capital. Como abordagem, as Opções Reais são as únicas que dão destaque para o potencial das oportunidades associado ao risco, com base no argumento de que a incerteza, por vezes, pode ser uma fonte de valor adicional (DAMODARAN, 2009).

Este trabalho apresenta uma análise exploratória de como as empresas de tecnologia avaliam seus projetos internos de TI em ambientes de incerteza. Os dados são levantados através de uma pesquisa Survey com 34 empresas situadas no estado do Rio Grande do Sul. A amostra foi escolhida por estar inserida em um ambiente de alta competitividade, exigindo flexibilidade e um bom gerenciamento de riscos por parte das empresas.

Este artigo está dividido em sete seções: (I) Introdução; (ii) Análise de Investimentos; (iii) Teoria de Opções Reais; (iv) Método; (v) Resultados; (vi) Discussão; e (vii) Conclusões.

\section{ANÁLISE DE INVESTIMENTOS}

Uma abordagem tradicional de análise de investimentos tem como objetivo a identificação da oportunidade mais rentável dentre as diversas opções disponíveis, 
buscando otimizar a alocação dos recursos financeiros. Os principais métodos de avaliação tradicionais partem do pressuposto básico de que o risco, ou a incerteza, não é considerado numa primeira análise pelos tomadores de decisão. Entre esses métodos pode-se destacar:

- Taxa Média de Retorno Contábil;

- Período de Pay-back;

- Taxa Interna de Retorno;

- Valor Presente Líquido;

A Taxa Média de Retorno Contábil, um dos métodos mais antigos de análise de negócios, baseia-se na comparação dos lucros líquidos contábeis com os custos iniciais de um projeto, através da adição de todos os lucros líquidos futuros e da sua divisão pelo investimento médio. Contudo, este método não considera o valor do dinheiro no tempo e os fluxos de caixa do projeto ao utilizar o lucro contábil como base de mensuração (GROPPELLI; NIKBAKHT, 1999).

O método do Pay-back define o número de períodos (geralmente em anos) necessários para a recuperação do investimento inicial. $\mathrm{O}$ método tradicional não leva em consideração o valor do dinheiro no tempo e não serve como medida de lucratividade, uma vez que as entradas e saídas de caixa, após o período de recuperação do investimento inicial, são ignoradas. Uma evolução desse método é o Pay-back ajustado, o qual considera o espaço de tempo entre o início do projeto e o momento quando os fluxos de caixa trazidos a valor presente tornam-se positivos (MONTEIRO, 2003).

A Taxa Interna de Retorno (TIR) é uma medida da taxa de rentabilidade. Por definição, a TIR é uma taxa de desconto que iguala o valor presente dos fluxos de caixa futuros ao investimento inicial. No entanto, uma análise de projetos apoiada apenas na TIR pode levar a resultados não realistas. Muitas vezes, a TIR calculada não é razoável para o reinvestimento de fluxos de caixa futuros ou também é possível que existam múltiplas taxas de retorno em um único projeto. No segundo caso, a difícil definição de qual taxa deveria ser utilizada na comparação com a taxa mínima torna o método pouco confiável (ROSS et al., 1998).

O Valor Presente Líquido (VPL), considerado um dos métodos tradicionais mais consistentes, é a diferença entre o valor presente das entradas e saídas de caixa presentes e futuras, descontadas a taxa de juros (taxa de desconto) (SMART et al., 2004). O ponto crítico da abordagem do VPL está na decisão de qual taxa de desconto utilizar. As taxas de desconto são influenciadas pelo nível de risco e pela duração do projeto e tendem a subir acompanhando taxas de juros e inflação (TRIGEORGIS, 1996).

Outra limitação que afeta o VPL e praticamente todos os métodos tradicionais está na necessidade de se assumir que o analista seja capaz de prever os fluxos de caixa futuros, e que as premissas adotadas permanecerão estáticas durante todo o projeto, sem qualquer intervenção dos gerentes em caso de resultados inesperados e desfavoráveis (SMART et al., 2004).

$\mathrm{Na}$ análise de projetos, quanto mais distante for o horizonte de tempo, maiores serão as incertezas e mais imprecisas serão as previsões dos fluxos de caixa. Desta forma, nos métodos tradicionais, erros na previsão dos fluxos de caixa podem levar à aceitação de um projeto que deveria ser rejeitado ou vice-versa. Além disso, a estimativa de taxas futuras é tanto difícil como incerta, e a premissa adotada pelos métodos de que a taxa de desconto é a mesma durante todo o projeto pode não ser realista (MONTEIRO, 2003). 
Brandão (2000) chama atenção para o fato da maioria das decisões de investimento partilham de três importantes características que as afetam diversos graus:

- O investimento pode ser parcialmente ou completamente irreversível: o custo inicial do investimento é pelo menos parcialmente perdido e a empresa não pode recuperá-lo totalmente caso mude de idéia;

- Existem incertezas acerca das futuras recompensas pelo investimento: deve-se avaliar as probabilidades de diferentes resultados, os quais significam maiores ou menores retornos e até mesmo perda parcial ou total de seu investimento; e

- Existe alguma flexibilidade em relação ao timming do investimento: é possível adiar a ação até obter mais informações, embora haja racionalidade limita quanto à informação, pois essa não é completa de modo a eliminar toda a incerteza.

Ao se analisar as duas últimas características acima, percebe-se que os modelos tradicionais de avaliação de investimento, embora eficientes em ambientes de risco controlado, não contemplam decisões em ambientes onde a incerteza e a flexibilidade afetam diretamente o nível de risco do projeto (SILVA, 2005). Para ambientes de investimento onde haja um alto risco e a necessidade de flexibilidade seja importante, é necessário o uso de modelos mais abrangentes, como é o caso da Teoria de Opções Reais.

\section{RISCOS EM TI E A TEORIA DE OPÇÕES REAIS}

As altas taxas de fracasso associadas a projetos de $\mathrm{TI}$ sugerem que as empresas precisam aumentar sua habilidade para identificar e gerenciar os riscos associados aos seus projetos (JIANG et al., 2001). Benaroch et al. (2006) identificam os principais riscos associados a projetos de TI. Wu e Ong (2008), ao abordarem estes riscos, classificam-nos em dois tipos: o primeiro, "riscos externos", vêem de fora da empresa. Toda empresa no mercado enfrenta incertezas externas, em oposição aos riscos internos que, segundo tipo, ocorrem dentro da empresa. Um mapa destes principais riscos é apresentado na Figura 1.

\begin{tabular}{|c|c|c|}
\hline \multirow{3}{*}{$\begin{array}{l}\text { Riscos } \\
\text { Externos }\end{array}$} & Benefícios & $\begin{array}{l}\text { - Super-estimativa ou falta de processos para } \\
\text { alcançar os benefícios }\end{array}$ \\
\hline & Tecnológico & $\begin{array}{l}\text { - A aplicação pode ser impraticável com a } \\
\text { tecnologia considerada, ou a tecnologia é } \\
\text { imatura; } \\
\text { - A introdução de uma nova tecnologia pode } \\
\text { tornar a aplicação obsoleta }\end{array}$ \\
\hline & Ambiental & $\begin{array}{l}\text { - Baixo número de clientes/fornecedores } \\
\text { /parceiros, demanda /adoção/uso; } \\
\text { - Demanda excede expectativas (monitorar }\end{array}$ \\
\hline
\end{tabular}




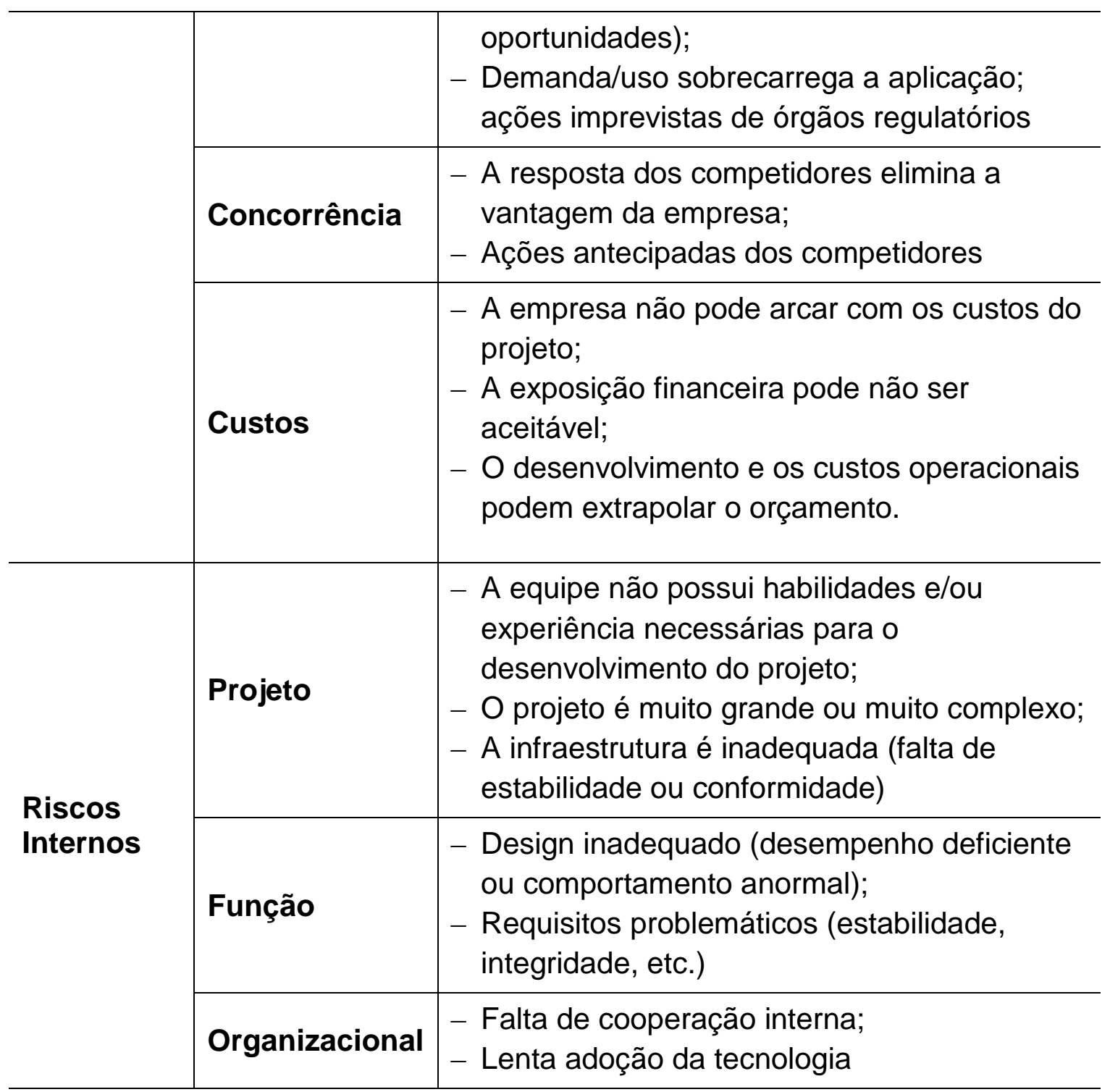

Figura 1 - Mapa de Riscos em investimentos de TI

Adaptado de (BENAROCH et al., 2006) e (WU; ONG, 2008)

Entre os métodos de análise de investimentos em ambientes de incerteza, a Teoria de Opções Reais vem sendo apontada como o novo paradigma na análise econômica de projetos. O termo "Opções Reais" foi cunhado pelo professor Stewart C. Myers do MIT em 1977, 4 anos após a publicação dos artigos seminais de Black \& Scholes (1973) e Merton (1973) sobre valoração de opções financeiras. Myers (1977) caracterizou as oportunidades de investimento das empresas em ativos reais como sendo análogas a opções de compra sobre esses ativos reais. Assim, a teoria reconhece e valoriza o fato de que as empresas têm o direito, mas não a obrigação, de investir uma quantia $X$ em um projeto que vale $Y$ (DIAS, 2005).

As Opções Reais são utilizadas para a avaliação de ativos reais, ou seja, os ativos que não são negociados no mercado, tais como projetos de investimento de capital, avaliação de propriedades intelectuais, avaliação de terras, avaliação de fontes de recursos naturais e avaliação de projetos de pesquisa. Seu conceito principal está fundamentado na teoria das opções financeiras, uma vez que as decisões gerenciais ao longo da vida útil de um projeto de investimento podem ser 
consideradas análogas às opções, pois existe um direito, mas não uma obrigação de se investir (SANTOS, 2001).

Uma Opção Real é a flexibilidade que um gerente tem para tomar decisões a respeito de ativos reais. No momento em que as novas informações vão surgindo e as incertezas sobre o fluxo de caixa vão se revelando, os administradores podem tomar decisões que venham a influenciar positivamente no valor final de um projeto (DIXIT; PINDYCK, 1994).

As decisões com as quais os administradores freqüentemente se deparam são: qual o momento certo de investir, de abandonar ou parar temporariamente um projeto, de modificar as características operacionais ou ainda trocar um ativo por outro. Desta forma, um projeto de investimento de capital pode ser considerado como um conjunto de opções reais sobre um ativo real (SANTOS, 2001).

Uma das diferenças importantes entre as Opções Reais e o método tradicional do VPL na análise dos investimentos é que as Opções Reais incentivam a realização de investimentos por fases, valorizando a aprendizagem entre as fases. A informação obtida numa fase serve para decidir sobre 0 projeto da fase subseqüente.

O valor das Opções Reais depende de seis variáveis básicas apontadas por Copeland e Antikarov (2001):

- Valor do ativo subjacente sujeito a risco: trata-se de um projeto, um investimento ou uma aquisição. Se o valor do ativo subjacente aumenta, o mesmo acontece com o valor de compra de uma opção;

- O preço de exercício: é o montante monetário investido para exercer a opção. À medida que o preço de exercício de uma opção aumenta, o valor da opção de compra diminui e o valor da opção de venda aumenta;

- Prazo de vencimento da opção: com o aumento do prazo de expiração, o valor da opção também aumenta;

- Desvio padrão do valor do ativo subjacente sujeito a risco: o valor de uma opção aumenta com o risco do ativo subjacente, porque os retornos de uma opção (de compra) dependem do valor do ativo subjacente que está acima do preço de exercício, e a probabilidade disso aumenta com a volatilidade do ativo subjacente;

- Taxa de juros livre de risco ao longo da vida da opção: à medida que a taxa de juros livre de riscos aumenta, o valor da opção também se eleva; e

- Os dividendos que podem ser pagos pelo ativo subjacente: são as saídas ou entradas de caixa ao longo de sua vida.

As opções reais são classificadas em categorias mutuamente excludentes de acordo com o grau de flexibilidade que oferecem. As opções mais comuns, segundo Pessoa (2008), são:

- Opção de abandono: se as condições de mercado piorarem drasticamente, os gerentes podem abandonar permanentemente as operações correntes e vender os equipamentos ou outros ativos a um valor residual. Copeland et al. (2000) compara este tipo de opção a uma vendas de ações do tipo americana. 
- Opção de parada: se as condições de mercado são instáveis, uma empresa pode não operar continuamente por todo tempo. Se os preços aumentarem suficientemente, as operações podem ser retomadas.

- Opção de mudança de uso: se os preços ou as demandas mudarem, o gerente pode mudar o mix de produtos da empresa, criando a flexibilidade no produto, ou alternativamente, manter a produção do mesmo produto e usar diferentes tipos de matérias-primas ou fornecedores, criando flexibilidade no processo.

- Opção de crescimento futuro: consiste em uma opção de compra no qual o valor das oportunidades de crescimento depende do investimento futuro efetuado pela empresa.

- Opção de deferir: uma das opções mais freqüentes nos investimentos em ativos reais é a opção de adiar o investimento. Muitas vezes, os projetos são analisados com base em um determinado fluxo de caixa esperado e uma taxa de desconto que possuem um VPL negativo. A gerência possui a opção de esperar antes de fazer 0 investimento para ver se as condições de mercado o justificam.

- Opção de expansão: ao iniciar um projeto, os gerentes podem ter a flexibilidade para alterá-lo de diversas formas ao longo de sua vida útil, ou seja, caso as condições de mercado se tornem mais favoráveis do que o esperado, a empresa pode expandir a escala de produção ou acelerar a utilização dos recursos, incorrendo no custo necessário a esta expansão.

- Opção de contração: de modo análogo ao da opção de expansão, existe a opção de contrair o investimento se as condições de mercado se tornarem mais fracas do que originalmente esperado. A gerência pode operar abaixo da capacidade ou até mesmo reduzir a escala de operações, salvando dessa forma parte dos investimentos planejados.

- Interação entre opções: na vida real, os projetos freqüentemente envolvem uma coleção de opções. Brennan \& Schwartz (1985) valoraram uma mina de cobre considerando a interação entre as seguintes opções reais (investimento, parada temporária, reativação e abandono da mina).

\section{MÉTODO}

Este trabalho possui uma natureza exploratória e objetivo descritivo. Para alcançar tal objetivo, foi utilizada uma abordagem quantitativa com o emprego de uma pesquisa Survey. A opção pela Survey se deve aos bons resultados apresentados na literatura sobre o uso desta técnica, tanto em pesquisas exploratórias, como na descrição de perfis de investimentos. Como exemplos, temse os trabalhos de Graham e Harvey (2001) e Oliveira et al. (2006) que utilizaram a técnica Survey para descrever as práticas de análise de investimentos em empresas nos EUA e Brasil respectivamente. 


\subsection{Instrumento de Pesquisa}

O objetivo desta pesquisa foi identificar em que situações e que métodos de análise de investimentos são utilizados pelas empresas na avaliação de seus projetos internos de TI. Também foram identificados os riscos a que as empresas estão expostas ao investirem em seus projetos e as principais ações que estas dispõem para minimizar estes riscos.

O instrumento utilizado para a pesquisa foi um questionário fechado constituído por cinco questões fechadas que abordam diferentes aspectos da avaliação de projetos em TI. Nas questões 1 e 2, os entrevistados foram solicitados a assinalar apenas uma das opções disponíveis para cada questão. A questão 3 permite a seleção de múltiplas opções, dependendo de quantos métodos de análise e empresa utilize. Na questão 4 , os respondentes selecionaram os quatro principais riscos a que suas empresas estão expostas e, na questão 5 , foram apontadas as principais ações adotadas para minimizar cada um dos riscos selecionados na questão 4.

O pré-teste do questionário foi realizado com um grupo de sete entrevistados, formados por especialistas em TI e profissionais ligados à análise de investimentos. Os resultados do pré-teste apontaram uma boa consistência do questionário, indicando apenas pequenas correções que foram implementadas no questionário final, apresentado no Apêndice A.

\subsection{Seleção da Amostra}

A pesquisa foi realizada com empresas de tecnologia situadas no estado do Rio Grande do Sul. A população amostrada foi um grupo de 112 empresas de tecnologia membros de uma associação de apoio ao desenvolvimento tecnológico. A amostra pesquisada é não probabilística e adotada por conveniência.

As características das empresas respondentes quanto ao número de funcionários e receita anual são apresentadas nas Figuras 1 e 2. A Figura 1 mostra como as empresas estão divididas percentualmente com relação ao número de funcionários.

\begin{tabular}{lll}
\hline $\mathbf{N}^{\circ}$ de funcionários & $\%$ & \\
\hline até 20 funcionários & $62 \%$ & \\
de 21 a 50 funcionários & $29 \%$ & \\
mais de 50 funcionários & $9 \%$ & $\square$
\end{tabular}

Figura 2 - Número de funcionários das empresas entrevistadas

A Figura 2 apresenta como as empresas amostradas estão divididas percentualmente com relação à receita líquida anual.

\begin{tabular}{lc}
\hline Receita líquida anual (R\$) & $\%$ \\
\hline até 1 milhão & $54 \%$ \\
entre 1 a 10 milhões & $36 \%$ \\
mais de 10 milhões & $10 \%$
\end{tabular}

Figura 3 - Receita líquida anual das empresas amostradas 


\subsection{Procedimento de Coleta de Dados}

A survey foi realizada no mês de julho de 2008 com questionários enviados eletronicamente, através de uma ferramenta Web administrada pela associação das empresas, ao responsável pela análise de investimentos de cada empresa. Todos os questionários foram retornados também via Web, através de e-mail.

\subsection{Análise dos Dados}

Do total de 112 questionários enviados, obteve-se um retorno de 34 questionários preenchidos (30\%). Todos os 34 questionários retornados foram validados e apenas 3 respostas foram identificadas como inconsistentes e retiradas da amostra.

Para a análise dos dados adotou-se a técnica comparativa (WOLCOTT, 1994). Nesta técnica, o padrão de comparação é feito internamente, confrontando diferentes segmentos que podem ser identificados na população pesquisada. Assim, é possível identificar, em base relativa, o que pode ser considerado grande ou pequeno no assunto em estudo.

\section{RESULTADOS}

Como resultado da pesquisa survey, obteve-se uma avaliação média de como as empresas de tecnologia, pertencentes à população amostrada, analisam projetos internos de TI e como gerenciam os riscos inerentes a estes projetos. A Figura 4 mostra como a exigência por análises de investimentos em projetos $\mathrm{Tl}$ tem se comportado nas empresas amostradas nos últimos 12 meses.

\begin{tabular}{|c|c|}
\hline Comportamentos & $\%$ \\
\hline Aumentou & $79 \%$ \\
\hline Manteve-se inalterada & $21 \%$ \\
\hline Diminuiu & $0 \%$ \\
\hline
\end{tabular}

Figura 4 - Resultados da Questão 1: Exigência por análise de investimentos em projetos de TI.

É possível visualizar, na Figura 4, que a exigência por análise de investimento dos projetos de $\mathrm{TI}$ vem aumentando para a maior parte das empresas $(79 \%)$, enquanto que para as demais $(21 \%)$ manteve-se inalterada. Nenhuma empresa apresentou uma diminuição na exigência por análises deste tipo de investimento.

A Figura 5 mostra em que situações as empresas utilizam a análise de investimentos para seus projetos internos de $\mathrm{Tl}$. 


\begin{tabular}{lrr}
\hline Práticas & \multicolumn{1}{c}{$\%$} \\
\hline Toda vez que um investimento em TI é necessário & $44 \%$ \\
A não ser que o benefício seja óbvio ou evidente & $12 \%$ \\
Caso o custo exceda ou possa exceder certo limite & $9 \%$ & \\
Quando é parte da estratégia de negócios & $24 \%$ & \\
Caso seja solicitado por um membro do grupo diretivo & $12 \%$ & $\square$ \\
Nenhuma das opções acima & $0 \%$ & \\
\hline
\end{tabular}

Figura 5 - Resultados da Questão 2: Prática para análise de investimentos em projetos de TI.

Percebe-se, na Figura 5, que a maioria das empresas realiza análise toda vez que um investimento em TI é necessário (44\%) ou quando é parte da estratégia de negócios (24\%). A Figura 6 apresenta quais os métodos mais utilizados pelas empresas amostradas para a análise dos seus projetos.

\begin{tabular}{lrl}
\hline Métodos & \multicolumn{1}{c}{$\%$} \\
\hline VPL - Valor Presente Líquido & $10 \%$ \\
TIR - Taxa Interna de Retorno & $8 \%$ \\
PAY-BACK & $21 \%$ & \\
ROI - Return on Investiment & $27 \%$ & \\
EVA - Economic Value Added & $8 \%$ \\
ROA - Real Options Analysis & $2 \%$ \\
Não são realizadas análises quantitativas & $23 \%$ \\
\hline
\end{tabular}

Figura 6 - Resultados da Questão 3: Métodos utilizados para análise de investimentos em projetos de TI.

A Figura 6 mostra que os métodos de análise de investimentos mais utilizados pelas empresas para seus projetos de TI são o ROI, utilizado por $27 \%$ das empresas, e o Pay-back, utilizado por $21 \%$ das mesmas. Chama atenção o número significativo de empresas que não realizam análises quantitativas de seus investimentos em $\mathrm{TI}(23 \%)$. Também se percebe o pouco uso, ou não conhecimento, do método ROA, mencionado por apenas $2 \%$ dos respondentes.

Uma provável justificativa para estes números pode estar no fato da maioria das empresas entrevistadas serem de pequeno porte. Pois, como mostram as Figuras 2 e 3, 62\% das empresas entrevistadas possuem até 20 funcionários e 54\% possuem uma receita liquida anual de até 1 milhão. Desta forma, é justificável que estas empresas façam uso do ROI e Pay-back como métodos de análise, pois precisam de um rápido retorno dos investimentos para pagar o risco tomado, já que novos projetos representam um grande custo de capital para as mesmas. De forma similar, o baixo uso do ROI pode estar relacionado à complexidade do método e a dificuldade destas empresas em manter um especialista neste tipo de análise.

A Figura 7 apresenta quais são os principais riscos a que as empresas veemse expostas ao investirem em seus projetos de TI. Na figura, é possível observar que os dois principais riscos encontrados são: Risco de o projeto ser muito grande ou muito complexo para ser implementado e Risco da infraestrutura ser inadequada e apresentar falta de estabilidade ou conformidade, ambos citados por $12 \%$ dos respondentes. Após, surgem o Risco do desenvolvimento ou dos custos operacionais extrapolarem o orçamento (10\%) e os riscos de Super-estimativa dos benefícios do projeto e da Equipe não possuir experiência necessária para o desenvolvimento do projeto, ambos com $9 \%$ de citação. 


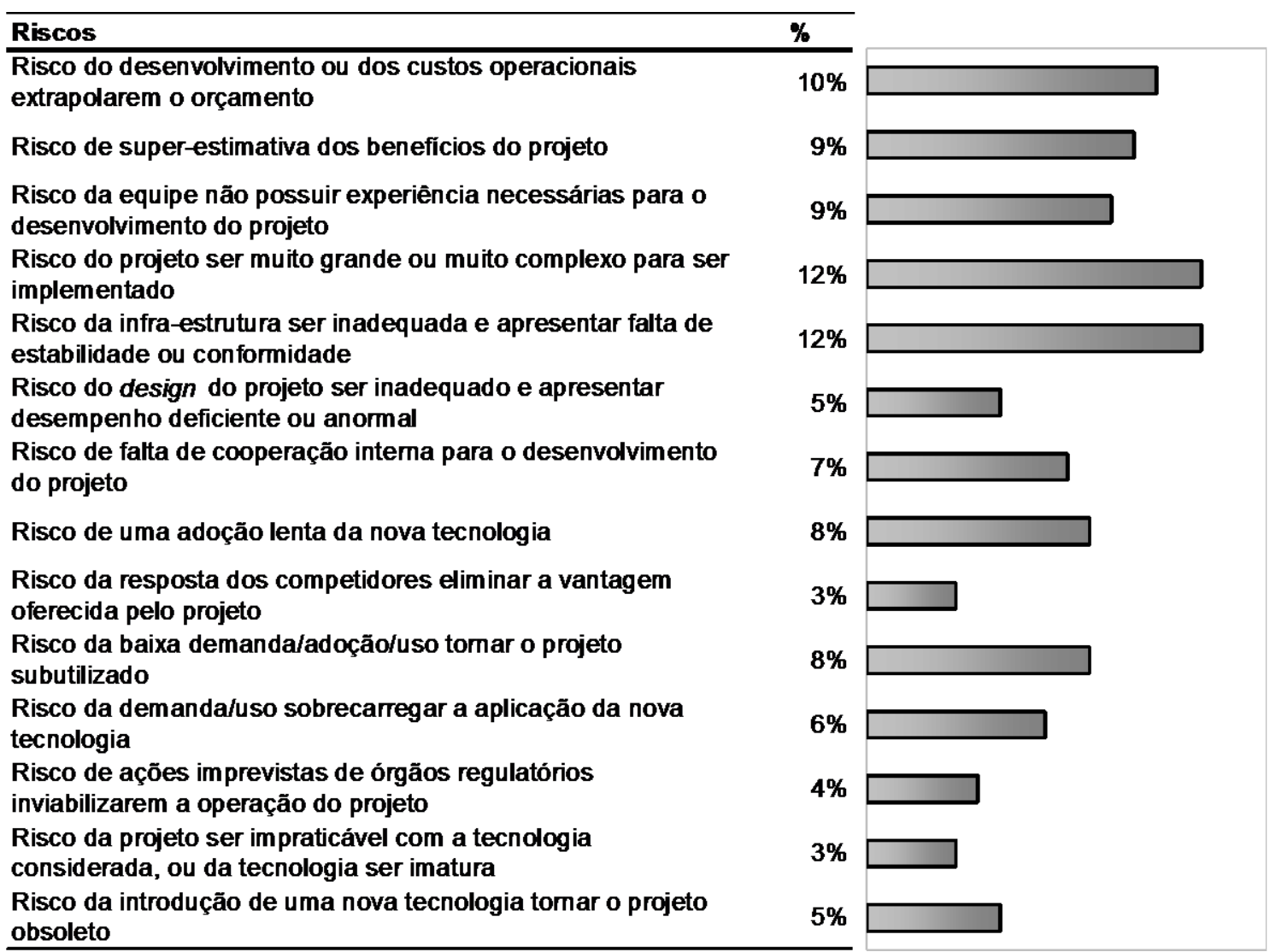

Figura 7 - Resultados da Questão 4: Riscos encontrados ao investir em projetos de TI.

A Tabela 1 apresenta o cruzamento das ações mais utilizadas para minimizar cada um dos riscos de investimento em TI. Os valores indicam o percentual de empresas que apontaram determinada ação como forma de contenção para cada um dos riscos envolvidos. Por exemplo, a ação de Desenvolver um projeto Piloto ou Protótipo foi apontada por $53 \%$ dos respondentes como a principal ação contra 0 Risco do desenvolvimento ou dos custos operacionais extrapolarem o orçamento.

As células em negrito na Tabela 1 mostram quais ações foram apontadas pela maioria como as mais adequadas para minimizar cada um dos tipos de riscos. Observa-se uma forte confiança na ação de Desenvolver um projeto Piloto ou Protótipo como solução para a maioria dos riscos envolvidos em projetos de $\mathrm{TI}$, seguida por Desenvolvimento incremental/estágios e Contratar tecnologia de terceiros. 
Tabela 1 - Ações adotadas para minimizar os riscos em projetos de TI.

\begin{tabular}{|c|c|c|c|c|c|c|c|}
\hline Ações & 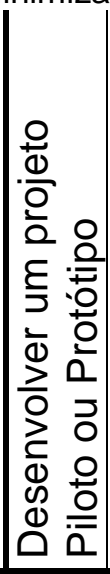 & 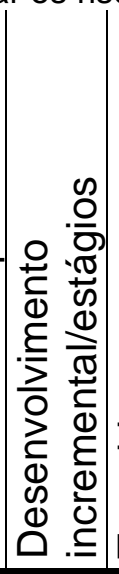 & 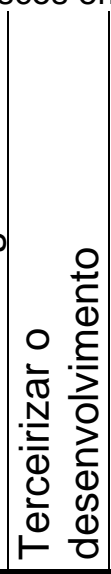 & 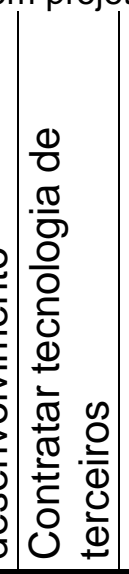 & $\begin{array}{l}\frac{0}{0} \\
\frac{0}{0} \\
\frac{0}{2} \\
0 \\
\frac{1}{\overline{0}} \\
\frac{1}{0} \\
\frac{0}{x} \\
\text { ய. }\end{array}$ & 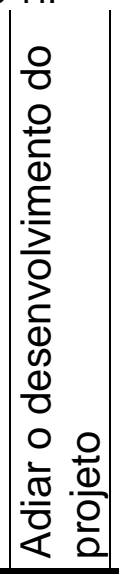 & $\begin{array}{l}\frac{0}{\frac{0}{0}} \\
\frac{0}{0} \\
\frac{0}{0} \\
0 \\
\frac{1}{0} \\
\frac{0}{0} \\
\frac{0}{0} \\
\frac{0}{\pi} \\
\frac{0}{4}\end{array}$ \\
\hline $\begin{array}{l}\text { Risco do desenvolvimento ou dos } \\
\text { custos operacionais extrapolarem o } \\
\text { orçamento }\end{array}$ & 0,53 & 0,27 & & 0,13 & & 0,07 & \\
\hline $\begin{array}{l}\text { Risco de super-estimativa dos } \\
\text { benefícios do projeto }\end{array}$ & 0,18 & 0,73 & & 0,09 & & & \\
\hline $\begin{array}{l}\text { Risco da equipe não possuir } \\
\text { experiência necessárias para o } \\
\text { desenvolvimento do projeto }\end{array}$ & 0,13 & 0,13 & 0,40 & 0,27 & & 0,07 & \\
\hline $\begin{array}{l}\text { Risco do projeto ser muito grande } \\
\text { ou muito complexo para ser } \\
\text { implementado }\end{array}$ & 0,25 & 0,50 & 0,13 & 0,06 & & 0,06 & \\
\hline $\begin{array}{l}\text { Risco da infra-estrutura ser } \\
\text { inadequada e apresentar falta de } \\
\text { estabilidade ou conformidade }\end{array}$ & 0,35 & 0,12 & 0,12 & 0,18 & & 0,24 & \\
\hline $\begin{array}{l}\text { Risco do design do projeto ser } \\
\text { inadequado e apresentar } \\
\text { desempenho deficiente ou anormal }\end{array}$ & 0,60 & 0,20 & & & & 0,20 & \\
\hline $\begin{array}{l}\text { Risco de falta de cooperação } \\
\text { interna para o desenvolvimento do } \\
\text { projeto }\end{array}$ & 0,36 & 0,09 & 0,18 & 0,27 & & 0,09 & \\
\hline $\begin{array}{l}\text { Risco de uma adoção lenta da } \\
\text { nova tecnologia }\end{array}$ & 0,14 & 0,07 & 0,14 & 0,50 & & 0,14 & \\
\hline $\begin{array}{l}\text { Risco da resposta dos } \\
\text { competidores eliminar a vantagem } \\
\text { oferecida pelo projeto }\end{array}$ & 0,50 & 0,17 & & & & & 0,33 \\
\hline $\begin{array}{l}\text { Risco da baixa } \\
\text { demanda/adoção/uso tornar o } \\
\text { projeto subutilizado }\end{array}$ & 0,50 & 0,44 & & & & 0,06 & \\
\hline $\begin{array}{l}\text { Risco da demanda/uso } \\
\text { sobrecarregar a aplicação da nova } \\
\text { tecnologia }\end{array}$ & 0,40 & 0,40 & & & 0,10 & & 0,10 \\
\hline $\begin{array}{l}\text { Risco de ações imprevistas de } \\
\text { órgãos regulatórios inviabilizarem a } \\
\text { operação do projeto }\end{array}$ & 0,22 & 0,22 & & 0,22 & & 0,11 & 0,22 \\
\hline $\begin{array}{l}\text { Risco da projeto ser impraticável } \\
\text { com a tecnologia considerada, ou }\end{array}$ & 0,13 & 0,13 & 0,13 & 0,38 & & & 0,25 \\
\hline
\end{tabular}




\begin{tabular}{l|l|l|l|l|l|l|l}
\hline da tecnologia ser imatura & & & & & & & \\
\hline $\begin{array}{l}\text { Risco da introdução de uma nova } \\
\text { tecnologia tornar o projeto obsoleto }\end{array}$ & $\mathbf{0 , 2 5}$ & $\mathbf{0 , 2 5}$ & 0,13 & 0,13 & & 0,13 & 0,13 \\
\hline
\end{tabular}

\section{DISCUSSÃO}

Esta pesquisa mostra que, para a maioria das empresas de tecnologia entrevistadas, vem ocorrendo um aumento da exigência de análise de investimentos em seus projetos internos de TI. Esta exigência vem ocorrendo toda vez que um investimento em TI é necessário ou, em outros casos, quando o projeto é parte da estratégia de negócio. No entanto, grande parte das empresas não realizam análises quantitativas de seus projetos e as que o realizam se concentram principalmente nos métodos $\mathrm{ROI}$ e Pay-back. Esses métodos priorizam uma rápida recuperação do capital investido, o que demonstra uma preocupação dessas empresas em recuperar o capital no curto prazo.

A preocupação com a rápida recuperação do capital é um comportamento característico quando se investe em ambientes de incerteza. Os riscos mais enfrentados pelas empresas entrevistadas em seus projetos internos de $\mathrm{TI}$ são com relação ao tamanho e a complexidade dos seus projetos e também com uma possível infraestrutura inadequada. No entanto, as empresas não utilizam métodos de análise de investimentos que ofereçam flexibilidade aos projetos, pois apenas $2 \%$ das empresas responderam utilizar o método de Opções Reais, que proporciona uma maior flexibilidade frente aos riscos de investimentos.

No trabalho de Benaroch et al. (2006), o autor realiza um mapeamento dos riscos envolvendo investimentos em projetos de $\mathrm{TI}$ e as contramedidas indicadas para minimizá-los, utilizando a teria de Opções Reais. O autor pesquisou uma organização de serviços financeiros irlandesa que possui uma carteira de projetos de larga escala em TI. Foram analisados os 50 projetos mais recentes e cruzadas as informações com um estudo extensivo da literatura. O resultado foi uma tabela indicativa das melhores opções para cada tipo de risco encontrado em projetos de TI.

A Tabela 2 foi adaptada de Benaroch et al. (2006) e mostra estes resultados na mesma formatação do questionário aplicado neste trabalho. As células de cor cinza, apresentadas na tabela, mostram as opções indicadas pelo trabalho de Benaroch como medida de contingência para cada um dos riscos de investimento. Os valores em cada uma das células indicam os mesmos resultados da Tabela 1. 
Tabela 2 - Ações adotadas para minimizar os riscos em projetos de TI.

\begin{tabular}{|c|c|c|c|c|c|c|c|}
\hline $\begin{array}{l}\text { Fatores de } \\
\text { Risco }\end{array}$ & 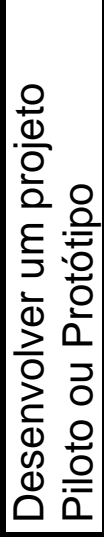 & 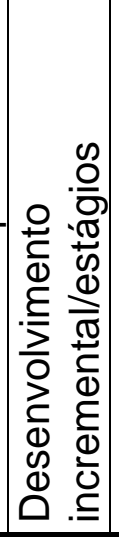 & 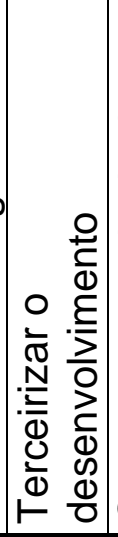 & 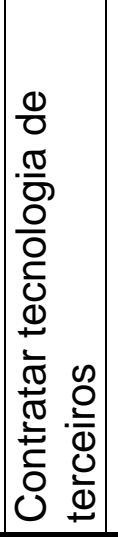 & 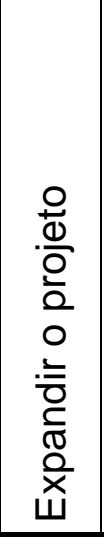 & 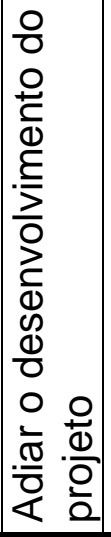 & $\begin{array}{l}\frac{0}{0} \\
\frac{0}{0} \\
\frac{0}{2} \\
0 \\
\frac{0}{0} \\
\frac{1}{0} \\
\frac{0}{0} \\
\frac{1}{0} \\
\frac{0}{4}\end{array}$ \\
\hline $\begin{array}{l}\text { Risco do desenvolvimento } \\
\text { ou dos custos operacionais } \\
\text { extrapolarem o orçamento }\end{array}$ & 0,53 & 0,27 & & 0,13 & & 0,07 & \\
\hline $\begin{array}{l}\text { Risco de super-estimativa } \\
\text { dos benefícios do projeto }\end{array}$ & 0,18 & 0,73 & & 0,09 & & & \\
\hline $\begin{array}{l}\text { Risco da equipe não possuir } \\
\text { experiência necessárias } \\
\text { para o desenvolvimento do } \\
\text { projeto }\end{array}$ & 0,13 & 0,13 & 0,40 & 0,27 & & 0,07 & \\
\hline $\begin{array}{l}\text { Risco do projeto ser muito } \\
\text { grande ou muito complexo } \\
\text { para ser implementado }\end{array}$ & 0,25 & 0,50 & 0,13 & 0,06 & & 0,06 & \\
\hline $\begin{array}{l}\text { Risco da infra-estrutura ser } \\
\text { inadequada e apresentar } \\
\text { falta de estabilidade ou } \\
\text { conformidade }\end{array}$ & 0,35 & 0,12 & 0,12 & 0,18 & & 0,24 & \\
\hline $\begin{array}{l}\text { Risco do design do projeto } \\
\text { ser inadequado e apresentar } \\
\text { desempenho deficiente ou } \\
\text { anormal }\end{array}$ & 0,60 & 0,20 & & & & 0,20 & \\
\hline $\begin{array}{l}\text { Risco de falta de } \\
\text { cooperação interna para o } \\
\text { desenvolvimento do projeto }\end{array}$ & 0,36 & 0,09 & 0,18 & 0,27 & & 0,09 & \\
\hline $\begin{array}{l}\text { Risco de uma adoção lenta } \\
\text { da nova tecnologia }\end{array}$ & 0,14 & 0,07 & 0,14 & 0,50 & & 0,14 & \\
\hline $\begin{array}{l}\text { Risco da resposta dos } \\
\text { competidores eliminar a } \\
\text { vantagem oferecida pelo } \\
\text { projeto }\end{array}$ & 0,50 & 0,17 & & & & & 0,33 \\
\hline $\begin{array}{l}\text { Risco da baixa } \\
\text { demanda/adoção/uso tornar } \\
\text { o projeto subutilizado }\end{array}$ & 0,50 & 0,44 & & & & 0,06 & \\
\hline $\begin{array}{l}\text { Risco da demanda/uso } \\
\text { sobrecarregar a aplicação } \\
\text { da nova tecnologia }\end{array}$ & 0,40 & 0,40 & & & 0,10 & & 0,10 \\
\hline $\begin{array}{l}\text { Risco de ações imprevistas } \\
\text { de órgãos regulatórios }\end{array}$ & 0,22 & 0,22 & & 0,22 & & 0,11 & 0,22 \\
\hline
\end{tabular}




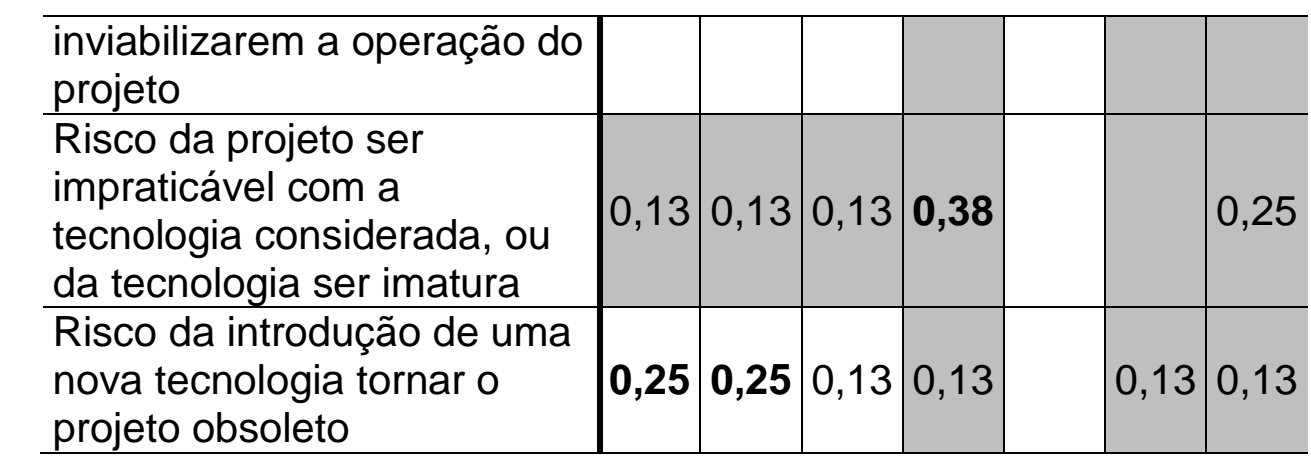

Fonte: adaptado de Benaroch et al. (2006).

Pode se observar pela Tabela 2 que as opções que flexibilizam os investimentos em $\mathrm{TI}$ utilizadas pelas empresas respondentes estão próximas das indicadas pelo trabalho de Benaroch et al. (2006), apesar dessas opções serem analisadas apenas qualitativamente pelas empresas, uma vez que a grande maioria não faz uso da teoria de Opções Reais. As maiores diferenças aparecem no momento de enfrentar os riscos de super-estimativa dos benefícios de projeto, risco da introdução de uma nova tecnologia tornar o projeto obsoleto e risco da demanda/uso sobrecarregar a aplicação da nova tecnologia.

Também é possível perceber a subutilização de algumas opções, como contratar tecnologia de terceiros, adiar o desenvolvimento do projeto e abandonar 0 projeto. Parte dessas diferenças no uso das opções deve-se, possivelmente, à falta de uma análise quantitativa das mesmas pelas empresas entrevistadas. $O$ uso de Opções Reais, nesse caso, pode indicar com maior clareza qual o retorno de cada opção aumentando a flexibilização e a alavancagem dos investimentos em TI.

\section{CONCLUSÃO}

A utilização da pesquisa Survey mostrou-se um método rápido e eficiente para descrever como as empresas de tecnologia avaliam seus projetos internos de TI em ambientes de incerteza. A pesquisa mostrou que na maioria das empresas pesquisadas a exigência por análises dos projetos de $\mathrm{TI}$ vem aumentando nos últimos 12 meses. Essa exigência ocorre, na maior parte dos casos, toda vez que um investimento em TI é necessário.

Também se observou que, apesar de estarem em um ambiente competitivo e dos projetos de $\mathrm{TI}$ possuírem uma série de riscos associados, grande parte das empresas (23\%) não realizam análises quantitativas de seus projetos. A maior parte das empresas (48\%), no entanto, utiliza pelo menos um entre os métodos ROI e Pay-back, o que indica uma preocupação na recuperação do capital investido no menor tempo possível, refletindo o ambiente de incerteza que caracteriza estes projetos.

Quanto aos riscos encontrados pelas empresas em seus projetos de $\mathrm{Tl}$ e as contramedidas utilizadas, percebe-se um pequeno desalinhamento no uso das opções ou ações de contramedidas com as alternativas propostas pela literatura, assim como uma certa subutilização destas opções com relação a alguns riscos. Essas diferenças, possivelmente, ocorrem pela falta de uso de um método quantitativo para mensurar o ganho de cada opção, como é o caso da teoria de Opções Reais. 
Observa-se que existe, entre as empresas de tecnologia pesquisadas, espaço para ganhos com relação à análise de investimentos em TI, pois métodos quantitativos como o de Opções Reais podem aumentar a flexibilização das empresas e o retorno dos projetos de TI em ambientes de risco.

\section{REFERÊNCIAS}

BENAROCH, M.; LICHTENSTEIN, Y.; ROBINSON, K. Real options in information technology risk management: an empirical validation of risk-option relationships. MIS Quarterly, Vol. 30, No. 4, December, p. 827-864, 2006.

BLACK, F.; SCHOLES, M. The Pricing of Options and Corporate Liabilities. Journal of Political Economy, vol. 81, p.637-659, 1973.

BRANDÃO, Luiz. Introdução as opções reais. Rio de janeiro, 2000. Disponível em: < www.iag.puc-rio.br/ brandao >. Acesso em: 27/07/2008.

BRENNAN, M.; SCHWART, E. Evaluating natural resources investments. Journal of Business, p. 137-157, 1985.

COPELAND, T. E.; KOLLER, T.; MURRIN, J. Avaliação de empresas: valuation. São Paulo: Makron Books, 2000.

COPELAND, Tom; ANTIKAROV, Vladimir. Opções Reais: um novo paradigma para reinventar a avaliação de investimento. Rio de Janeiro: Campus, 2001.

DAMODARAN, Aswath. Gestão Estratégica do Risco. Bookman: Porto Alegre, 2009.

DIAS, Marco A. Guimarães. Opções Reais híbridas com aplicações em Petróleo. 2005. 509 f. Tese (Doutorado em Engenharia Industrial) - Programa de PósGraduação em Engenharia Industrial, PUC-Rio, Rio de Janeiro.

DIXIT, A. K.; PINDYCK, R. S. Investment under uncertainty. Princeton, New Jersey: Princeton University Press, 1994.

GRAHAM, J. R.; HARVEY, C. R. The Theory and Practice of Corporate Finance: Evidence from the Field. Journal of Financial Economics, vol. 60, p.187-243, 2001.

GROPPELLI, A. A.; NIKBAKHT, E. Administração Financeira. 3. ed. São Paulo: Saraiva, 1999.

JIANG, J. J., KLEIN, G., DISCENZA, R. Information System Success as Impacted by Risks and Development Strategies. IEEE Transactions of Engineering Management, v. 48, n. 1 , february, p. $46-55,2001$

MERTON, R.C. Theory of Rational Option Pricing. Journal of Economics and Management Science, vol.4, spring, p.141-183, 1973.

MONTEIRO, Regina Caspari. Contribuições da abordagem de avaliação de Opções Reais em ambientes econômicos de grande volatilidade - uma ênfase no cenário latino-americano. 2003. 200 f. Dissertação (Mestrado em Controladoria e Contabilidade) - Faculdade de Economia, Administração e Contabilidade, USP, São Paulo.

MYERS, S.C. Determinants of Corporate Borrowing. Journal of Financial Economics, November, p.147-175, 1977. 
OLIVEIRA, A. B. S.; PARISI, C.; PEREIRA, A. C.; GIACOMAZI, L. C. Uma Pesquisa Exploratória sobre a Análise de Investimentos em Sistemas ERP e o seu acompanhamento pelas Empresas do Estado de São Paulo. Congresso Brasileiro de Custos (CBC), Anais do XIII Congresso Brasileiro de Custos, 13, 2006. Meio digital.

PESSOA, Gerisval Alves. A aplicação da Teoria das Opções Reais em tempo discreto na mineração de ferro. Diponível em: < www.artigocientifico.com.br/acervo/6/64/1671.html >. Acesso em: 01/08/2008.

PORTER, M. E. Capital Disadvantage: America's Failing Capital Investment System. Harvard Business Review, Sep/Oct, p. 65-82, 1992.

ROSS, S.A.; WESTERFIELD, R.W.; JORDAN, B.D. Princípios de Administração Financeira. São Paulo: Atlas, 1998.

SANTOS, Elieber Mateus. Um Estudo Sobre a Teoria das Opções Reais aplicada à análise de investimentos em Projetos de Pesquisa e Desenvolvimento (P\&D). 2001, 186 f. Dissertação (Mestrado em Engenharia de Produção) - Programa de PósGraduação em Engenharia de Produção, Escola Federal de Engenharia de Itajubá, Itajubá.

SANTOS, Elieber Mateus; PAMPLONA, Edson de Oliveira. Teoria das Opções Reais: uma atraente opção no processo de análise de investimentos. Revista de Administração, v. 40, n. 3, jul/ago/set, p. 235-252, 2005.

SILVA, S. M. Além da Análise de Investimento Tradicional: Um Caso no Segmento Hoteleiro. IX Congresso Internacional de Custos. Florianópolis, 2005.

SMART, S. B.; MEGGINSON, W. L.; GITMAN, L. J. Corporate Finance. Manson: Thomson/South-Western, 2004. 1040p.

TRIGEORGIS, L. Real Options: Managerial Flexibility and Strategy in Resource Allocation. Cambridge, MA: The MIT Press, 1996.

WOLCOTT, H. F. Transforming qualitative data: description, analysis, and interpretation. Thousand Oaks: SAGE Publications, Inc., 1994. 433p.

WU, L.; ONG, C. Management of information technology investment: A framework based on a Real Options and Mean - Variance theory perspective. Technovation 28 (2008) 122-134. 


\section{Apêndice A - Questionário da Pesquisa Survey}

1. Nos últimos 12 meses, a exigência por análises de investimentos em projetos de $\mathrm{TI}$ (projetos para upgrade interno) na sua empresa, tem aumentado, diminuído ou manteve-se inalterada?
Aumentou
Manteve-se
inalterada
Diminuiu

2. Qual das opções abaixo melhor descreve a prática utilizada na sua empresa para a realização da análise de investimentos em projetos internos de TI?

$\begin{array}{ll}\text { investimento em TI é necessário } & \text { Toda vez que um } \\ \text { benefício seja óbvio ou evidente } & \text { A não ser que o } \\ \text { ou possa exceder certo limite } & \text { Caso o custo exceda } \\ \text { estratégia de negócios } & \text { Quando é parte da } \\ \text { por um membro do grupo diretivo } & \text { Caso seja solicitado } \\ \text { acima } & \text { Nenhuma das opções }\end{array}$

3. Quais métodos de análise de investimentos são utilizados pela sua empresa para a análise de projetos internos de TI? (marque mais de uma opção se necessário)

$\begin{array}{ll}\square \text { Líquido } & \text { VPL - Valor Presente } \\ \square & \text { TIR - Taxa Interna de }\end{array}$

Retorno

PAY-BACK

Investiment

ROI - Return on

Value Added

EVA - Economic

Analysis

ROA - Real Options

análises quantitativas

Não são realizadas

4. Quais os principais riscos a que sua empresa se vê exposta ao investir em projetos internos de TI? (marque os quatro principais riscos)

Risco do

desenvolvimento ou dos custos operacionais extrapolarem o orçamento

estimativa dos benefícios do projeto

Risco de super- 
Risco da equipe

responsável não possuir habilidades e/ou experiência necessárias para o desenvolvimento do projeto

muito grande ou muito complexo para ser implementado

Risco do projeto ser

Risco da infra-

estrutura ser inadequada para o projeto e apresentar falta de estabilidade ou conformidade

Risco do design do

projeto ser inadequado e apresentar desempenho deficiente ou anormal

Risco de falta de

cooperação interna para o desenvolvimento do projeto

lenta da nova tecnologia

Risco de uma adoção

Risco da resposta

dos competidores eliminar a vantagem oferecida pelo projeto

Risco da baixa

demanda/adoção/uso tornar o projeto subutilizado

Risco da

demanda/uso sobrecarregar a aplicação da nova tecnologia

Risco de ações

imprevistas de órgãos regulatórios inviabilizarem a operação do projeto

Risco da projeto ser

impraticável com a tecnologia considerada, ou da tecnologia ser imatura

de uma nova tecnologia tornar o projeto obsoleto

Risco da introdução

Nenhum dos riscos

acima (descrever...)

5. Quais são as ações adotadas pela empresa para controlar os riscos de investimentos selecionados na questão anterior? *(as opções abaixo foram apresentadas para cada um dos riscos selecionados na questão 4).

\begin{tabular}{ll}
\hline projeto Piloto ou Protótipo & Desenvolver um \\
\hline incremental/estágios & Desenvolvimento \\
\hline desenvolvimento & Terceirizar o \\
de terceiros & Contratar tecnologia \\
\hline & Expandir o projeto \\
desenvolvimento do projeto & Adiar o \\
\hline & Abandonar o projeto \\
acima (descrever...) & Nenhuma das opções
\end{tabular}

